\title{
A large de novo 9p21.3 deletion in a girl affected by astrocytoma and multiple melanoma
}

Simona Frigerio ${ }^{1}$, Vittoria Disciglio², Siranoush Manoukian³ ${ }^{3}$ Bernard Peissel³, Gabriella Della Torre ${ }^{1}$, Andrea Maurichi ${ }^{4}$, Paola Collini ${ }^{5}$, Barbara Pasini ${ }^{3,6}$, Giacomo Gotti ${ }^{7}$, Andrea Ferrari ${ }^{7}$, Licia Rivoltini ${ }^{1}$, Maura Massimino ${ }^{7}$ and Monica Rodolfo ${ }^{1 *}$

\begin{abstract}
Background: Association of melanoma, neural system tumors and germ line mutations at the 9p21 region in the CDKN2A, CDKN2B and CDKN2BAS genes has been reported in a small number of families worldwide and described as a discrete syndrome in melanoma families registered as a rare disease, the melanoma-astrocytoma syndrome.

Case presentation: We here studied two young patients developing melanoma after radiotherapy for astrocytoma, both reporting lack of family history for melanoma or neural system tumors at genetic counselling. Patient $\mathrm{A}$ is a girl treated for anaplastic astrocytoma at 10 years and for multiple melanomas on the scalp associated to dysplastic nevi two years later. Her monozygotic twin sister carried dysplastic nevi and a slow growing, untreated cerebral lesion. Direct sequencing analysis showed no alterations in melanoma susceptibility genes including CDKN2A, CDK4, MCIR and MITF or in TP53. By microsatellite analysis, multiplex ligation-dependent probe amplification, and array comparative genomic hybridization a deletion including the CDKN2A, CDKN2B and CDKN2BAS gene cluster was detected in both twin sisters, encompassing a large region at 9p21.3 and occurring de novo after the loss of one paternal allele.

Patient B is a boy of 7 years when treated for astrocytoma then developing melanoma associated to congenital nevi on the head 10 years later: sequencing and multiplex ligation-dependent probe amplification revealed a normal profile of the CDKN2A/CDKN2B/CDKN2BAS region. Array comparative genomic hybridization confirmed the absence of deletions at 9p21.3 and failed to reveal known pathogenic copy number variations.

Conclusions: By comparison with the other germ line deletions at the CDKN2A, CDKN2B and CDKN2BAS gene cluster reported in melanoma susceptible families, the deletion detected in the two sisters is peculiar for its de novo origin and for its extension, as it represents the largest constitutive deletion at 9p21.3 region identified so far. In addition, the two studied cases add to other evidence indicating association of melanoma with exposure to ionizing radiation and with second neoplasm after childhood cancer. Melanoma should be considered in the monitoring of pigmented lesions in young cancer patients.
\end{abstract}

Keywords: Melanoma-astrocytoma syndrome, 9p21.3 deletion, CDKN2A, CDKN2BAS, MLPA, Oligo array-CGH

\footnotetext{
* Correspondence: monica.rodolfo@istitutotumori.mi.it

1 Department of Experimental Oncology and Molecular Medicine, Fondazione IRCCS Istituto Nazionale dei Tumori, via Venezian 1, Milan 20133, Italy

Full list of author information is available at the end of the article
} 


\section{Background}

The combination of melanoma and neural system tumors (NST) was described in melanoma families where the diseases occurred in different family members or concomitantly, and was registered as a rare disease, the melanoma-astrocytoma syndrome (OMIM 155755).

Three families from France, UK and USA showing association of melanoma, NST and germ line deletions of part or of the entire $C D K N 2 A$ locus, as well as of $C D K N 2 B$ and the non-coding $C D K N 2 B A S$ genes, have been described [1-3]. In other studies, families prone to melanoma and NST lacked deletions in the 9p21 region, although other altered loci causing the syndrome have not been identified [4-7]. Missense mutations in CDKN2A genes were also described in one French and two Italian families reporting melanoma associated with meningioma and neuroblastoma respectively $[8,9]$. The analysis of other genes located in this region, such as KLHL9 and PTPRD, failed to identify inherited mutations in melanoma and NST kindreds $[7,10]$.

While the genetic basis for NST remains largely unidentified [11], several genes associated to melanoma predisposition besides $C D K N 2 A$ have been recently identified [12].

In a recent study we genetically characterized a series of 21 pediatric melanoma treated at our Institute [13]: two cases developing melanoma after NST were studied for deletions at the 9p21 region. Here we report the results of these analyses.

\section{Case presentation}

We report the case of a female Italian patient (A) treated for anaplastic astrocytoma (10 yr) who developed multiple melanomas on the scalp associated to dysplastic nevi two years later (Figure 1). In the following 8 years when she was followed clinically at our Institute, she developed 10 melanomas on the head, neck, trunk and leg. She also developed neurotechoma (8 yr) and neurofibroma (18 yr). A tectal mesencephalic lesion growing along 10 years and producing hydrocephalus was the final reason for her death $(20 \mathrm{yr})$. Her monozygotic twin sister (TS) carried dysplastic nevi and a slow growing, untreated cerebral lesion at parietal cortex (22 yr). The pedigree profile at genetic counselling lacked neoplastic diseases in the maternal lineage while in the paternal lineage an uncle and his son had unspecified neoplastic disease.

The sequencing analysis showed wild type sequences for CDKN2A, CDK4, and MC1R; in addition, TP53 mutations and the MITF E318K variant identified in familial melanoma [14,15] were not found (data not shown) (see Additional file 1: Methods). The allele status of microsatellite markers in the $C D K N 2 A$ gene region was analyzed in patient $\mathrm{A}$, her parents and TS (see Additional file 2: Table S1). For the markers D9S974, D9S942, D9S1748 and D9S1749 a single peak was detected for the patient and the TS, while for the parents two alleles with at least one allele of the same size were shown. For each marker, the allele found had the same size of one of the maternal allele (see Additional file 3: Figure S1) indicating the occurrence of a deletion in the CDKN2A locus in the paternal allele.

Multiplex Ligation-dependent Probe Amplification (MLPA) showed hemizygosity of CDKN2A-CDKN2B gene region for patient $\mathrm{A}$ and TS, and normal profiles for the parents (see Additional file 4: Figure S2), supporting a de novo origin. The analysis of metaphase chromosomes from EBV-immortalized lymphocytes by FISH hybridization using as probe the $\mathrm{C} 5$ cosmid spanning about $50 \mathrm{~kb}$ of the chromosomal region from CDKN2A to $C D K N 2 B$ genes further confirmed the deletion in the two sisters (data not shown). Oligo array-comparative genomic hybridization (aCGH) analysis was performed to confirm MLPA results and to better define the deletion breakpoints. The analysis of ratio profiles revealed for patient $\mathrm{A}$ and TS a deletion at the $9 \mathrm{p} 21.3$ chromosomal region of approximately $2,135 \mathrm{Mb}$ including part of the CDKN2BAS
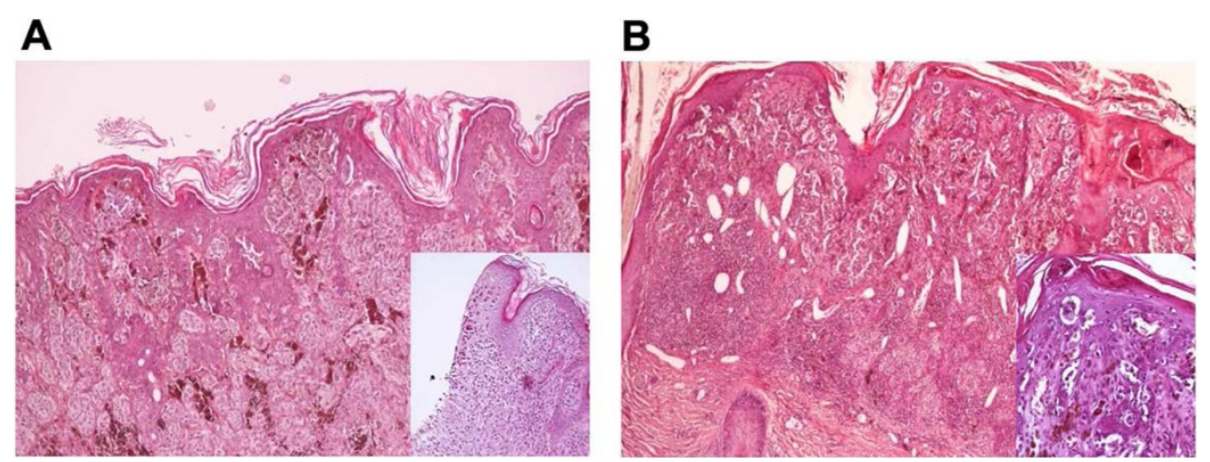

Figure 1 Histopathology of the initial biopsy specimens excised from the head of patient A. Specimens from the head neoplasms of the patient revealing a superficial spreading melanoma with epithelioid appearance associated with a compound nevus (inset) (A) or in the absence of melanocytic nevi (B). Hematoxylin and eosin, magnification 10x. 


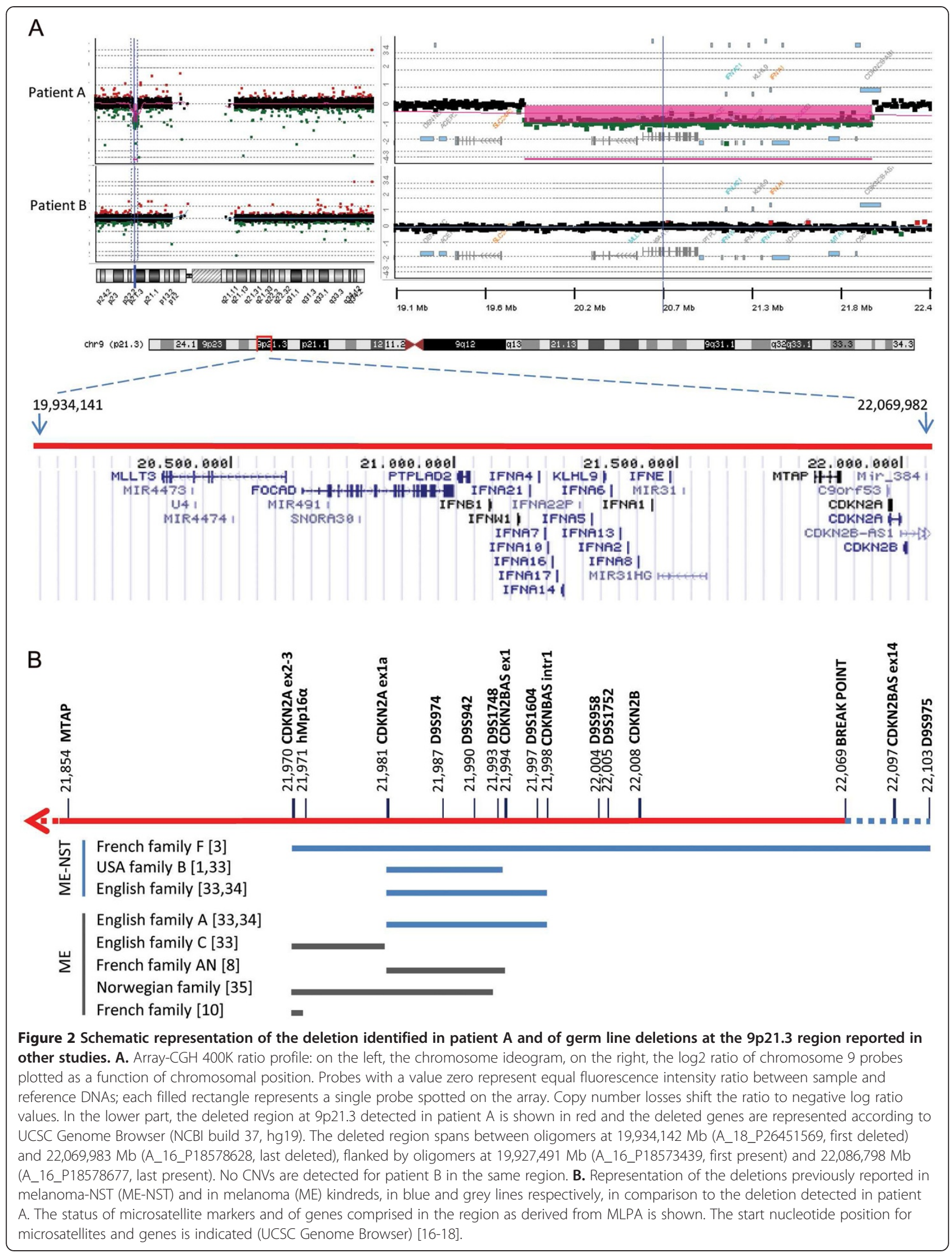


gene, CDKN2B, CDKN2A, MTAP, MIR31, the IFNA gene cluster, KLHL9, IFNW1, IFNB1, PTPLAD2, FOCAD, MIR491, SNORA30, MLLT3, MIR4473 and MIR4474 (Figure 2A).

The second case studied, patient $\mathrm{B}$, is a boy developing melanoma associated to congenital nevi on the head $(17 \mathrm{yr})$ after astrocytoma $(7 \mathrm{yr})$. Five years later he developed fatal pleuric rhabdomyosarcoma. His pedigree lacked neoplastic diseases. No alterations were revealed by sequence analysis in $C D K N 2 A$ gene except for the rs3814960 and rs11515 variants in the 3'UTR and 5'UTR regions, which are rather common single nucleotide polymorphisms (SNPs) in melanoma patients [19]. In addition, he carried wild type CDK4, MC1R and MITF genes, and a normal profile of the $C D K N 2 A-C D K N 2 B$ region was shown by MLPA. aCGH analysis showed a normal ratio profile at the 9 p21.3 region (Figure $2 \mathrm{~A}$ ) and revealed copy number gains on $4 \mathrm{p} 14$ and $6 \mathrm{q} 24.3$ of uncertain clinical significance, which deserve further studies and analyses in other patients with similar diseases (see Additional file 5: Table S2).

\section{Conclusions}

Germ line mutations at $C D K N 2 A$ locus are generally inherited founder mutations having a common ancestral origin, while de novo mutations appear to be exceedingly rare events [20], thus marking a peculiarity in the genetic of patient A. Although the precise endpoints of the deletion were not determined here, by aCGH it was shown to span from $19,934,142$ to $22,069,983 \mathrm{Mb}$, thus being larger than those previously mapped by Pasmant [3]. In fact, in addition to the CDKN2A/CDKN2B/CDKN2BAS gene cluster, the deletion extends in the telomeric end to comprise a large region up to the MLLT3 gene.

Similarly to the other deletions detected in association with melanoma and NST, the deleted region includes part of the CDKN2BAS gene, which on the contrary is not always included in the deletions occurring in melanoma kindreds lacking NST, as schematized in Figure 2B. $C D K N 2 B A S$ gene, or ANRIL (antisense non-coding RNA in the INK4 locus), consists of 19 exons spanning a region of $126.3 \mathrm{~kb}$ located within the CDKN2B-CDKN2A gene cluster, and is transcribed in the antisense orientation in a long non-coding RNA involved in epigenetic silencing of $C D K N 2 B-C D K N 2 A$ locus by polycomb repressive complexes [21]. Genome-wide association studies have identified SNPs in CDKN2BAS associated with susceptibility to NST as well as to melanoma [22,23]; interestingly, $C D K N 2 B A S$ has been identified as a risk locus also for other cancers and diseases [24]. Among the other genes comprised in the deleted region, FOCAD has been shown deleted in glioma tumors [25]. Furthermore, in patient B, $\mathrm{CGH}$ analysis showed copy number gains on $4 \mathrm{p} 14$ and 6q24.3 chromosomal regions involving TCF25 and KLF3 genes respectively, which encode for transcription factors, representing potential candidates for further studies. In fact, TCF25, has been involved in embryonic development expressed in brain [26], and $K L F 3$, has been reported to show rearrangements in different cancer types [27].

Our study shows that 9p21.3 deletion is neither necessary nor sufficient for the NST-melanoma syndrome. Of note, both patients developed melanoma on their head after radiotherapy for astrocytoma, thus adding to other evidence suggesting association of melanoma with exposure to ionizing radiation [28-32]; in addition, the TS of patient A, who was not treated for NST, did not develop melanoma, although she carried an identical 9p21.3 deletion (see Additional file 6: Figure S3). It results that young cancer patients treated with radiotherapy should be considered at risk for developing melanoma and their pigmented lesions should be carefully monitored by expert clinicians. In fact, although melanoma is a rare disease in the healthy childhood population, it occurs more frequently as second malignant neoplasm after childhood cancer [33] and should be closely monitored by regularly screen in the follow-up of survivors, which have an approximate 2.5-fold increased risk of melanoma [34]. Furthermore, children with genetic syndromes may have unique pathophysiologies that necessitate careful evaluation and follow-up of skin alterations, since often dermatologists find unusual and atypical correspondences between clinic and dermoscopic parameters and the histological ones [35]. A multifaceted approach including a thorough clinical history, visual examination and dermoscopic evaluation of suspicious skin lesions is recommended to increase the sensitivity and specificity for diagnosing melanoma in these young patients.

\section{Consent}

Written informed consent was obtained from the patients' parents for genetic counselling, DNA analyses, scientific research and study purposes for all family members. The consent form was approved by the local ethical committee (Comitato Etico Centrale IRCCS Lombardia). A copy of the written consent is available for review by the Editor of this journal.

\section{Additional files}

\section{Additional file 1: Methods.}

Additional file 2: Table S1. Primers of the microsatellite markers used in the study. Start and end positions are reported according to UCSC Genome Browser (NCBI Build 37, hg19).

Additional file 3: Figure S1. Microsatellite analysis revealing loss of the paternal allele in patient A and TS. Homozygosity or hemizygosity at microsatellite loci was analyzed by PCR and amplification products analyzed with the ABI Prism Peak Scanner Software.

Additional file 4: Figure S2. Results of MLPA of the $9 p$ region in patient A, TS and parents. Results obtained with MLPA arrays for the 9p21 region ordered according to the genomic location of the probes. 
Gene dosage quotients for the 41 probes and relative ID numbers are shown, for patient A and TS in full bars, and for parents in empty bars. The deletion detected in the two sisters extends from CDKN2B to MLLT3 genes, and includes CDKN2A, MTAP, IFNA1, KLH9, IFNW1, and IFNBI genes; in contrast, ELAV2 and TEK centromeric to CDKN2B and GLDC and DOCK8 telomeric to MLLT3 showed normal gene dosage quotients indicating retention of both gene copies.

Additional file 5: Table S2. List of chromosomal aberrations detected by aCGH (400K) in patient B not reported in the Database of Genomic Variants (http://dgv.tcag.ca/dgv/app/home?ref=GRCh37/hg19). CNVs in non coding regions were detected on 7p12.3, 7q11.22, 19q13.11 chromosomal regions. A large region on 14q11.2 contains genes poorly characterize functionally. CNVs on 4p14 and 16q24.3 involve genes of potential interest since they have been involved in the regulation of cell growth and death.

Additional file 6: Figure S3. Results of array-CGH of the 9p21.3 region in patient $\mathrm{A}$ and her twin sister. aCGH analysis showed an identical 9p21.3 deletion of $\sim 2,135 \mathrm{Mb}$.

\section{Abbreviations}

NST: Neural system tumor; MLPA: Multiplex ligation-dependent probe amplification; TS: Twin sister; SNP: Single nucleotide polymorphism; aCGH: array Comparative Genomic Hybridization; CNV: Copy number variation.

\section{Competing interests}

The authors declare that they have no competing interests.

\section{Authors' contributions}

SF carried out the PCR amplifications, sequencing studies, MLPA and microsatellite analyses and helped to draft the manuscript. VD carried out array-CGH, the analysis of the results and helped to write the final manuscript. AM and PC carried out the clinical and the pathologic analyses and helped to draft the manuscript. SM, BP and PP the genetic counselling and helped to draft the manuscript. GDT designed the study and the genetic analysis. GG, AF and MM conceived of the study, and participated in its design and coordination and helped to draft the manuscript. MR and LR designed the study, defined the results and finalized the manuscript. All authors read and approved the final manuscript.

\section{Acknowledgements}

This work was supported by a grant from the Ministry of Health and by the Italian Association for Cancer Research (AIRC).

\section{Author details}

'Department of Experimental Oncology and Molecular Medicine, Fondazione IRCCS Istituto Nazionale dei Tumori, via Venezian 1, Milan 20133, Italy. ${ }^{2}$ Department of Experimental Oncology and Molecular Medicine, Functional Genomics and Bioinformatics Core Facility, Fondazione IRCCS Istituto Nazionale dei Tumori, via Venezian 1, Milan 20133, Italy. ${ }^{3}$ Unit of Medical Genetics, Department of Preventive and Predictive Medicine, Fondazione IRCCS Istituto Nazionale dei Tumori, Milan, Italy. ${ }^{4}$ Unit of Melanoma and Sarcoma, Department of Surgery, Fondazione IRCCS Istituto Nazionale dei Tumori, Milan, Italy. ${ }^{5}$ Department of Pathology, Fondazione IRCCS Istituto Nazionale dei Tumori, Milan, Italy. ${ }^{6}$ Current address: Department of Medical Science, University of Turin, Turin, Italy. ${ }^{7}$ Pediatric Unit, Fondazione IRCCS Istituto Nazionale dei Tumori, Milan, Italy.

\section{Received: 11 October 2013 Accepted: 5 May 2014}

Published: 17 May 2014

\section{References}

1. Bahuau M, Vidaud D, Jenkins RB, Bieche I, Kimmel DW, Assouline B, Smith JS, Alderete B, Cayuela JM, Harpey JP, Caille B, Vidaud M: Germ-line deletion involving the INK4 locus in familial proneness to melanoma and nervous system tumours. Cancer Res 1998, 58:2298-2303.

2. Randerson-Moor J, Kukalizch K, Bishop TD: Melanoma-Astrocytoma syndrome. Atlas Genet Cytogenet Oncol Haematol 2006, 10:288-291.

3. Pasmant E, Laurendeau I, Héron D, Vidaud M, Vidaud D, Bièche I: Characterization of a germ-line deletion, including the entire INK4/ARF locus, in a melanoma-neural system tumor family: identification of
ANRIL, an antisense noncoding RNA whose expression coclusters with ARF. Cancer Res 2007, 67:3963-3969.

4. Nielsen K, Ingvar C, Måsbäck A, Westerdahl J, Borg A, Sandberg T, Jonsson $\mathrm{N}$, Nagel J, Olsson H: Melanoma and nonmelanoma skin cancer in patients with multiple tumours-evidence for new syndromes in a population-based study. Br J Dermatol 2004, 150:531-536.

5. Marian C, Scope A, Laud K, Friedman E, Pavlotsky F, Yakobson E, Bressac-de Paillerets B, Azizi E: Search for germline alterations in CDKN2A/ARF and CDK4 of 42 Jewish melanoma families with or without neural system tumours. Br J Cancer 2005, 92:2278-2285.

6. Goldstein AM, Chan M, Harland M, Gillanders EM, Hayward NK, Avril MF, Azizi E, Bianchi-Scarra G, Bishop DT, Bressac-de Paillerets B, Bruno W, Calista D, Cannon Albright LA, Demenais F, Elder DE, Ghiorzo P, Gruis NA, Hansson J, Hogg D, Holland EA, Kanetsky PA, Kefford RF, Landi MT, Lang J, Leachman SA, Mackie RM, Magnusson V, Mann GJ, Niendorf K, Newton Bishop J, et al: High-risk melanoma susceptibility genes and pancreatic cancer, neural system tumors, and uveal melanoma across GenoMEL. Cancer Res 2006, 66:9818-9828.

7. Solomon DA, Kim JS, Yang XR, Tucker MA, Goldstein AM, Samuels Y, Waldman T: Lack of inherited mutations of PTPRD in familial melanoma and melanoma-astrocytoma syndrome. Pigment Cell Melanoma Res 2009, 22:489-491.

8. Laud K, Marian C, Avril MF, Barrois M, Chompret A, Goldstein AM, Tucker MA, Clark PA, Peters G, Chaudru V, Demenais F, Spatz A, Smith MW, Lenoir GM, Bressac-de Paillerets B, French Hereditary Melanoma Study Group: Comprehensive analysis of CDKN2A (p16INK4A/p14ARF) and CDKN2B genes in 53 melanoma index cases considered to be at heightened risk of melanoma. J Med Genet 2006, 43:39-47.

9. Ghiorzo P, Gargiulo S, Pastorino L, Nasti S, Cusano R, Bruno W, Gliori S, Sertoli MR, Burroni A, Savarino V, Gensini F, Sestini R, Queirolo P, Goldstein AM, Scarrà GB: Impact of E27X, a novel CDKN2A germ line mutation, on p16 and p14ARF expression in Italian melanoma families displaying pancreatic cancer and neuroblastoma. Hum Mol Genet 2006, 15:2682-2689.

10. Lesueur F, de Lichy M, Barrois M, Durand G, Bombled J, Avril MF, Chompret A, Boitier F, Lenoir GM, French Familial Melanoma Study Group, Bressac-de Paillerets B, Baccard M, Bachollet B, Berthet P, Bonadona V, Bonnetblanc JM, Caron O, Chevrant-Breton J, Cuny JF, Dalle S, Delaunay M, Demange L, De Quatrebarbes J, Doré JF, Frénay M, Fricker JP, Gauthier-Villars M, Gesta P, Giraud S, Gorry P, et al: The contribution of large genomic deletions at the CDKN2A locus to the burden of familial melanoma. Br J Cancer 2008, 99:364-370

11. Andersson U, Wibom C, Cederquist $K$, Aradottir S, Borg A, Armstrong GN, Shete S, Lau CC, Bainbridge MN, Claus EB, Barnholtz-Sloan J, Lai R, II'yasova D, Houlston RS, Schildkraut J, Bernstein JL, Olson SH, Jenkins RB, Lachance DH, Wrensch M, Davis FG, Merrell R, Johansen C, Sadetzki S, The Gliogene Consortium, Bondy ML, Melin BS: Germline rearrangements in families with strong family history of glioma and malignant melanoma, colon, and breast cancer. Neuro Oncol 2014, in press.

12. Hill VK1, Gartner JJ, Samuels Y, Goldstein AM: The genetics of melanoma: recent advances. Annu Rev Genomics Hum Genet 2013, 14:257-279.

13. Daniotti M, Ferrari A, Frigerio S, Casieri P, Miselli F, Zucca E, Collini P, Della Torre G, Manoukian S, Peissel B, Bono A, Santinami M, Parmiani G, Rivoltini L, Pilotti S, Rodolfo M: Cutaneous melanoma in childhood and adolescence shows frequent loss of INK4A and gain of KIT. $J$ Invest Dermatol 2009, 129:1759-1768.

14. Yokoyama S, Woods SL, Boyle GM, Aoude LG, MacGregor S, Zismann V, Gartside M, Cust AE, Haq R, Harland M, Taylor JC, Duffy DL, Holohan K, Dutton-Regester K, Palmer JM, Bonazzi V, Stark MS, Symmons J, Law MH, Schmidt C, Lanagan C, O'Connor L, Holland EA, Schmid H, Maskiell JA, Jetann J, Ferguson M, Jenkins MA, Kefford RF, Giles GG, et al: A novel recurrent mutation in MITF predisposes to familial and sporadic melanoma. Nature 2011, 480:99-103.

15. Ghiorzo P, Pastorino L, Queirolo P, Bruno W, Tibiletti MG, Nasti S, Andreotti V, Genoa Pancreatic Cancer Study Group, Paillerets BB, Bianchi Scarrà G: Prevalence of the E318K MITF germline mutation in Italian melanoma patients: associations with histological subtypes and family cancer history. Pigment Cell Melanoma Res 2013, 26:259-262.

16. Mistry SH, Taylor C, Randerson-Moor JA, Harland M, Turner F, Barrett JH, Whitaker L, Jenkins RB, Knowles MA, Bishop JA, Bishop DT: Prevalence of 9 p21 deletions in UK melanoma families. Genes Chromosomes Cancer 2005, 44:292-300 
17. Randerson-Moor JA, Harland M, Williams S, Cuthbert-Heavens D, Sheridan E, Aveyard J, Sibley K, Whitaker L, Knowles M, Bishop JN, Bishop DT: A germline deletion of p14(ARF) but not CDKN2A in a melanoma-neural system tumour syndrome family. Hum Molec Genet 2001, 10:55-62.

18. Knappskog S, Geisler J, Arnesen T, Lillehaug JR, Lønning PE: A novel type of deletion in the CDKN2A gene identified in a melanoma-prone family. Genes Chromosomes Cancer 2006, 45:1155-1163.

19. Goldstein AM, Chaudru V, Ghiorzo P, Badenas C, Malvehy J, Pastorino L, Laud K, Hulley B, Avril MF, Puig-Butille JA, Miniere A, Marti R, Chompret A, Cuellar F, Kolm I, Mila M, Tucker MA, Demenais F, Bianchi-Scarra G, Puig S, De-Paillerets BB: Cutaneous phenotype and MC1R variants as modifying factors for the development of melanoma in CDKN2A G101W mutation carriers from 4 countries. Int J Cancer 2007, 121:825-831.

20. Hayward NK: Genetics of melanoma predisposition. Oncogene 2003, 22:3053-3062

21. Aguilo F, Zhou MM, Walsh MJ: Long noncoding RNA, polycomb, and the ghosts haunting INK4b-ARF-INK4a expression. Cancer Res 2011, 71:5365-5369

22. Rajaraman P, Melin BS, Wang Z, McKean-Cowdin R, Michaud DS, Wang SS, Bondy M, Houlston R, Jenkins RB, Wrensch M, Yeager M, Ahlbom A, Albanes D, Andersson U, Freeman LE, Buring JE, Butler MA, Braganza M, Carreon T, Feychting M, Fleming SJ, Gapstur SM, Gaziano JM, Giles GG, Hallmans G, Henriksson R, Hoffman-Bolton J, Inskip PD, Johansen C, Kitahara CM, et al: Genome-wide association study of glioma and meta-analysis. Hum Genet 2012, 131:1877-1888.

23. Bishop DT, Demenais F, lles MM, Harland M, Taylor JC, Corda E, Randerson-Moor J, Aitken JF, Avril MF, Azizi E, Bakker B, Bianchi-Scarrà G, Bressac-de Paillerets B, Calista D, Cannon-Albright LA, Chin-A-Woeng T, Debniak T, Galore-Haskel G, Ghiorzo P, Gut I, Hansson J, Hocevar M, Höiom V, Hopper JL, Ingvar C, Kanetsky PA, Kefford RF, Landi MT, Lang J, Lubiński J, et al: Genome-wide association study identifies three loci associated with melanoma risk. Nat Genet 2009, 41:920-925.

24. Pasmant $E$, Sabbagh A, Vidaud M, Bièche I: ANRIL, a long, noncoding RNA, is an unexpected major hotspot in GWAS. FASEB J 2011, 25:444-448.

25. Brockschmidt A, Trost D, Peterziel H, Zimmermann K, Ehrler M, Grassmann H, Pfenning PN, Waha A, Wohlleber D, Brockschmidt FF, Jugold M, Hoischen A, Kalla C, Waha A, Seifert G, Knolle PA, Latz E, Hans VH, Wick W, Pfeifer A, Angel P, Weber RG: KIAA1797/FOCAD encodes a novel focal adhesion protein with tumour suppressor function in gliomas. Brain 2012 135:1027-1041.

26. Cai Z1, Wang Y, Yu W, Xiao J, Li Y, Liu L, Zhu C, Tan K, Deng Y, Yuan W, Liu M, Wu X: HNULP1, a basic helix-loop-helix protein with a novel transcriptional repressive domain, inhibits transcriptional activity of serum response factor. Biochem Biophys Res Commun 2006, 343:973-981.

27. Lyng H1, Brøvig RS, Svendsrud DH, Holm R, Kaalhus O, Knutstad K, Oksefjel $H$, Sundfør K, Kristensen GB, Stokke T: Gene expressions and copy numbers associated with metastatic phenotypes of uterine cervical cancer. BMC Genomics 2006, 7:268.

28. Guérin S, Dupuy A, Anderson H, Shamsaldin A, Svahn-Tapper G, Moller T, Quiniou E, Garwicz S, Hawkins M, Avril MF, Oberlin O, Chavaudra J, de Vathaire F: Radiation dose as a risk factor for malignant melanoma following childhood cancer. Eur J Cancer 2003, 39:2379-2786.

29. Eliason MJ, Hansen CB, Hart M, Porter-Gill P, Chen W, Sturm RA, Bowen G, Florell SR, Harris RM, Cannon-Albright LA, Swinyer L, Leachman SA: Multiple primary melanomas in a CDKN2A mutation carrier exposed to ionizing radiation. Arch Dermatol 2007, 143:1409-1412.

30. Figl A, Thirumaran RK, Ugurel S, Gast A, Hemminki K, Kumar R, Schadendorf D: Multiple melanomas after treatment for Hodgkin lymphoma in a non-Dutch p16-Leiden mutation carrier with 2 MC1R high-risk variants. Arch Dermatol 2007, 143:495-499.

31. Haddy N, Mousannif A, Paoletti C, Dondon MG, Shamsaldin A, Doyon F, Avril MF, Fragu P, Labbé M, Lefkopoulos D, Chavaudra J, Robert C, Diallo I, de Vathaire F: Radiotherapy as a risk factor for malignant melanoma after childhood skin hemangioma. Melanoma Res 2012, 22:77-85.

32. Sturiale CL, Sabatino G, Albanese A, Balducci M, Lauriola L, Pennacchia I, Maira G: Subcutaneous malignant melanoma of the scalp surgical flap after brain irradiation for anaplastic astrocytoma. J Neurooncol 2012, 106:203-207.

33. Braam Kl, Overbeek A, Kaspers GJ, Ronckers CM, Schouten-van Meeteren AY, Van Dulmen-Den Broeder E, Veening MA: Malignant melanoma as second malignant neoplasm in long-term childhood cancer survivors: A systematic review. Pediatr Blood Cancer 2012, 58:665-674.

34. Pappo AS, Armstrong GT, Liu W, Srivastava DK, McDonald A, Leisenring WM, Hammond S, Stovall M, Neglia JP, Robison LL: Melanoma as a subsequent neoplasm in adult survivors of childhood cancer: A report from the childhood cancer survivor study. Pediatr Blood Cancer 2013, 60:461-466.

35. Haliasos HC, Zalaudek I, Malvehy J, Lanschuetzer C, Hinter H, Hofmann-Wellenhof R, Braun R, Marghoob AA: Dermoscopy of benign and malignant neoplasms in the pediatric population. Semin Cutan Med Surg 2010, 29:218-231.

doi:10.1186/1471-2350-15-59

Cite this article as: Frigerio et al:: A large de novo 9p21.3 deletion in a girl affected by astrocytoma and multiple melanoma. BMC Medical Genetics 2014 15:59.

\section{Submit your next manuscript to BioMed Central and take full advantage of:}

- Convenient online submission

- Thorough peer review

- No space constraints or color figure charges

- Immediate publication on acceptance

- Inclusion in PubMed, CAS, Scopus and Google Scholar

- Research which is freely available for redistribution 